http://dx.doi.org/10.12795/PH.1989.v04.i02.31

\title{
LAS PALABRAS MILITARES EN LA OBRA DE SEBASTIÁN SCHERTLIN VON BURTENBACH. APROXIMACIÓN AL ESTUDIO DEL LÉXICO DEL FRÜHNEUHOCHDEUTSCH
}

\author{
Julio Sánchez \\ Departamento de Filologías integradas \\ Cátedra de Filología alemana
}

Introducción.

Sebastián Schertlin von Burtenbach (1496-1577) vivió una vida de intensa actividad guerrera que le llevó de simple soldado a una posición sólida e influyente.

Comenzó a los 23 años su vida militar y participó a lo largo de su vida en todas las campañas importantes de la época. Estuvo en la batalla de Pavía en 1524, en la Guerra de los Campesinos en 1525, en el asalto de Roma por las tropas imperiales en 1527. Luchó contra los turcos en diferentes campañas desde 1522, participando en la defensa de Viena en 1529, donde ganó una importante batalla. Allí el emperador le arma caballero por segunda vez, la primera fue después del triunfo de Pavía.

En 1532 compró el castillo de Burtenbach y en 1534 consigue del emperador la carta de nobleza.

Después de adoptar la doctrina de la reforma lucha contra el emperador en la guerra de Esmalcada (1546), como jefe de la infantería de las ciudades protestantes. Con la victoria de los católicos tiene que huir a Suiza y después a Francia, donde presta su apoyo al rey francés en las luchas contra el emperador. En 1553 vuelve amnistiado a su castillo.

Hasta el final de su vida ocupó cargos importantes en el ejército imperial y en la ciudad de Augsburgo. 
Sus memorias comenzaronse a escribir hacia la mitad del siglo, usando probablemente diarios para el período anterior. Narra en ellas, de forma fuertemente personalizada, sus campañas militares, las controversias y disputas con sus vecinos, sus relaciones con los aliados en la liga de Esmalcalda y el emperador. Nos relata también las noticias más importantes de su tiempo y nos provee de información sobre su familia de una forma muy próxima a la crónica. Schertlin encargará a su hijo que escriba acerca de sus últimos momentos, su muerte y su entierro.

Schertlin cuenta de forma concisa y clara lo que ve y lo que vive; su forma de escribir es escueta, no hay descripciones ni recreamientos literarios.

He utilizado en mi trabajo la edición que de esta obra publicó Ottmar F. H. Schönhuth cuyo título completo es Leben und Thaten des weiland wohledlen und gestrengen Herrn Sebastian Schertlin von Burtenbach, durch ihn selbst deutsch beschrieben. Nach der eigenen Handschrift des Ritters urkundlichtre herausgegeben von Ottmar F. H. Schönhuth. Münster 1858. Druck und Verlag der Aschendorffschen Buchhandlung. Por esta razón están escritos los sustantivos con minúscula, práctica que era común en el Renacimiento. Las citas del diccionario de los hermanos Grimm llevan los sustantivos en minúscula tal como aparecen en el citado diccionario.

\section{Estudio del lexico.}

Entre los nombres de armas de fuego cortas y de uso personal encontramos sólo la curiosa forma faustbüchsen (pág. 154), esta palabra no está registrada en el estudio de Franz Helbling Das militärische Fremdwort ${ }^{1}$ aunque si aparece en el Diccionario de los hermanos Grimm ${ }^{2}$ con el significado de «pistola»; la voz Pistole usada desde comienzos del siglo $\mathrm{XV}^{3}$ no aparece ni una sóla vez.

En cuanto a la terminología de las armas de fuego largas y personales existe más variedad y no poca originalidad, Schertlin nos da los nombres de doppelhaken (pág. 128), hantrohr (pág. 87), feuerbüchsen (pág. 14), éste último no es citado por Helbling aunque si es aclarado perfectamente en el diccionario de los hermanos Grimm ${ }^{4}$, y bürschbüchsen (p. 154) que lleva antepuesto el adjetivo lange, hace referencia a un arma de caza ${ }^{5}$ con el caño muy largo.

En franca oposición con la opinión de Helbling. "Von allen Waffengattungen erscheint das Geschützwesen am frühesten im Gewande des Fremdworts. "Artillerie» erscheint schon zu Beginn des 16. Jahrhunderts und ist das ganze Jahrhundert hindurch in zahlreichen Formen allgemein gebraucht» ${ }^{6}$. Schertlin no usa

1 Franz Helbling, Das militärische Fremdwort des 16. Jahrhunderts en Zeitschrift für deutsche Wortforschung, herausgegeben von Friedrich Kluge, vierzenhter Band, Straßburg 1872.

2 Jacob und Wilhelm Grimm. Deutsches Wörterbuch. Deutscher Taschenbuch Verlag. München 1984, pág. 1381, t. 3.

3 Etymologie. Herkunftswörterbuch der deutschen Sprache. Band 7. Mannheim. Dudenverlag 1963. pág. 513.

4 «fuewerbüchsen das sind kurze stück ungeferlich vier schuen lang, daraus fuewerkugel in die besatzungen zu schießen». Grimm op. cit. pág. 1589, t. 3.

5 «die bürsch = was birsch, venatio», Grimm op. cit. pág. 549, t. 2.

6 Helbling op. cit. pág. 26. 
ni una sola vez la palabra Artillerie, él prefiere términos menos innovadores tales como geschütz (pág. 12), schwere geschutz (pág. 105) stück reder (pág. 93), groß und klein geschützt (pág. 12), stückbüchsen (pág. 3), grob geschütz (pág. 45), feldgeschützt (pág. 18) y handtgeschütz ${ }^{7}$ (pág. 128); usa también formas en diminutivo típicas del dialecto suavo y de otros dialectos del sur del territorio de habla alemana, así stücklin büchsen (pág. 55), stucklin büchsen auf räder (pág. 123).

A veces estas armas no se denominan con palabras genéricas sino según el nombre particular de cada pieza, de acuerdo con el tipo y calibre. Schertlin cita tres tipos de cañones: acht falconet (pág. 6), vier singerin (pág. 35), vier quarthonen (pág. 35) las tres muy próximas a las formas italianas de donde provienen ${ }^{8}$.

Quarthonen y singerin pertenecen a la artillería de asedio y falconet a la de campaña. Schertlin utiliza también la denominación 12 apostel (pág. 44) para denominar a un grupo de cañones, suponemos que 12, usado por los protestantes en la guerra de Esmalcalda. Es curioso que, siendo Schertlin militar de profesión, use términos tan genéricos y poco profesionales, como los vistos más arriba, y recurra con tan poca frecuencia a los nombres específicos de las piezas de artillería.

Con respecto a las armas de filo aparecen spiess (paǵ. 8) y seiten weren (pág. 97), para designar la lanza larga usada por los lansquenetes, aunque la palabra pike ya existía desde alrededor de 1500 en la lengua alemana ${ }^{9}$, también aparecen schwert (pág. 17), degen (pág. 87), dolch (pág. 174), hellemparten (pág. 50) y säbel (pág. 65).

Mención especial merece la palabra schäfflin (pág. 17) que no es registrada por Helbling pero que tanto en el diccionario de los hermanos Grimm ${ }^{10}$ como Hegaur ${ }^{11}$ la registran como «lanza corta», «jabalina», relacionándola ambos también con la forma francesa «javelin». Como arma para golpear cita únicamente fausthamer (pág. 5).

En lo concerniente a la munición nos da las siguientes palabras: bulfer, $k u$ geln [...] und munition (pág. 20); esta última palabra tiene un sentido mucho más amplio que el actual y hace referencia a todas las necesidades de pertrechos y avituallamiento de un ejército ${ }^{12}$. Con el significado de «bala», «proyectil» tenemos también las voces de plei (pág. 128) y lot (pág. 154) ${ }^{13}$.

7 Se trata de un «kleineres, in der hand zu führendes geschütz, im gegensatz zu dem groben, hakenbüchsen, kartaunen, mörser u.a.». Grimm op.cit. pág. 391 t. 10.

8 Helbling op. cit. pág. 26-27.

9 «Das Wort wurde um 1500 aus gleichbe. frz. pique entleht, das wohl als Substantivbildung zu frz. piquer «stechen usw» (vgl pikiert) gehört». Duden Band 7 op. cit. pág. 511.

10 «schäfflein das kurzes spiesz» Grimm op. cit. pág. 2034 t. 14.

11 Mientras que Hegaur emparenta Schäfflin con la voz Schaft = mango, asta, en el diccionario de los hermanos Grimm se la emparenta con la voz de m.h.d. schavelin o schevelin.

Engelbert Hegaur. Leben und Taten des weiland wohledeln ritters Sebastian Schertlin von Burtenbach durch ihn selbst deutsch beschrieben. Verlegts Albert Lange. München 1910. pág. 275.

12 Hans Schulz. Deutsches Fremdwörterbuch. Walter de Gruyter. Berlin 1942 pág. 161 t. 2.

13 Bajo la grafía loht encontramos la definición «stuck blei als geschusz». Grimm op. cit. pág. 1204 t. 12. 
La terminología relativa a los instrumentos de defensa o protección es también escasa, usa harnasch (pág. 87) y platten (pág. 103) con el sentido de «armadura» o «coraza»; para «casco» o «almete» encontramos las denominaciones de sturm hut (pág. 129) y helmlin (pág. 116), forma diminutiva del sustantivo Helm. No hay gran innovación o diferencias con respecto al alemán actual en los diferentes tipos de banderas que aparecen en el texto; la forma más común fenhlein puede tener dos significados: el de «estandarte» ${ }^{14}$, y sobre todo el de «grupo armado», «unidad de combate» ${ }^{14}$. Schertlin usa tres palabras que se podrían traducir por «bandera principal»: rennfane (pág. 29), hauptfane (pág. 44) y hauptpanier (pág. 12).

Tenemos también algunas otras palabras que denominan objetos accesorios empleados en el oficio de la guerra como son sporen (pág. 17, rittersporen (pág. 174), handtschuh (pág. 17), Schuch (pág. 87).

Con respecto a las denominaciones para «ejército»y «tropa» nos encontramos con una cierta variedad de términos, entre los que sobresalen dos: el primero sería Haufen, con expresiones muy claras como kay. May. hauffen (pág. 3), schwäbischen pundtshauffen (pág. 4), heuffen zu ross und fuss (pág. 107) o konigs hauffen (pág. 11) y otras más oscuras como gaistlichen hauffen (pág. 111) o hellen hauffen (pág. 4); también puede aparecer con pequeñas modificaciones en la grafía como der halb hauf (pág. 15). La segunda sería volck, con expresiones como bapsts volck (pág. 3), kriegsvolck (pág. 6), fussgehendem volck (pág. 63), übelgezogens verzagts volck (pág. 68).

Con menos frecuencia aparece la voz Heer, la mayor parte de las veces formando palabras compuestas como herzug (pág. 11) o aigen her (pág. 22), obrister feldher (pág. 26) heresmacht (pág. 130) y herszug (pág. 151). Otras expresiones que aparecen son kriegsleute (pág. 5), y gesind (pág. 54) ninguna de ellas es recogida por Helbling. Esta última voz merece especial atención, frecuentemente nos la encontramos con el sentido de «tropa» o «ejército» ${ }^{15}$, aunque también con el actual de «criados», «criadas», «servidumbre», «servicio», como en hofgesind (pág. 7). Ambos conceptos, el de servidumbre y tropa, aparecen confundidos porque sin duda en la época uno implicaba el otro en buen número de casos.

Algunas expresiones designan, de forma menos precisa, a un conjunto de tropas usando el adjetivo stark en ejemplos como über 12.000 starck (pág. 3).

Entre los préstamos aparecen el francés arme (pág. 58) referido a un «ejército que se mueve por tierra» y el español armada (en tres ocasiones) (págs. 75, 104 y 159) con el sentido de «conjunto de naves de guerra» en todos los casos. En contra, pues, de la opinión de Helbling ${ }^{16}$ el término Armada aparece ya en la primera mitad del siglo XVI.

14 «Und zog von Ingolstatt herauf, usid nam Neuburg ein cassiert die 3 feudlein knecht ohne wer und harnasch und fendlein, ...» Schönhuth op. cit. pág. 47. En esta frase tenemos en muy corto espacio ambos valores, el de unidad de combate en primer lugar y el de estandarte.

15 «das heergefolge, die heerschar, das kriegsvolk» Grimm op. cit. pág. 4108 t. 5.

16 «Erst kurz vor dem Dreißigjährigen Kriege treffen wir dafür vereinzelt das spanische «Armada», häufig dagegen das französische «Armee». Helbling op. cit. pág. 22. 
Atendiendo a los cargos en el ejército y el nombre de los mandos, las denominaciones autóctonas son las más frecuentes. Aparecen nombres extranjeros para designar cargos en ejércitos extranjeros. Se citan los siguientes nombres turcos: Bassa (pág. 2), Alewaschant (pág. 159), Bartanwascha (pág. 159) y Ochiali (pág. 159); estos tres últimos empleados cuando hace la reseña de la batalla de Lepanto. Usa los términos franceses conestable (pág. 70) y admiral (pág. 27) para designar estos cargos en el ejército francés.

Encontramos la palabra general (pág. 69) sin estar unida a ninguna otra palabra y con el significado de «comandante supremo de todo el ejército» en los escritos del año 1547. Esto no se ajusta a la información que nos da el diccionario etimológico de Friedrich Kluge ${ }^{17}$, aunque aparece designando a una personalidad italiana al mando de un ejército italiano. En la misma época vemos esta palabra asociada a otros términos militares en la expresión de claro origen francés generalcapitain (pág. 29) y más tarde en general obrister feldhauptman (pág. 168).

Siguiendo con los cargos a la cabeza del ejército, encontramos con que profusión y variedad se usa el término Oberst, que aparece como obrister feldhaupmann (pág. 5), obrister feldher (pág. 26), obrister leutenant (pág. 91), obristen locotenent (pág. 107), obrist feldmarchalckamt (pág. 113), kreiss obrister (pág. 131), obrister (pág. 11), también bajo la grafía obrist (pág. 164), y el ya conocido general obrister feldhauptman (pág. 168). Schertlin nos da asimismo otras denominaciones para la persona que ostenta el más alto cargo del ejército: marschalck (pág. 23), palabra que no es usada por Helbling pero que sí aparece con esta acepción en el Diccionario de los hermanos Grimm ${ }^{18}$, feldmarschälck (pág. 42), grossmarschalk (pág. 29) y veldhern (pág. 45).

Siguiendo con las denominacione de jefes en el ejército, nos parece muy interesante la expresión gross und cleine hansen (pág. 115), Hanse que no aparece ni en Helbling ni en Horn ${ }^{19}$, tiene el valor de «señor», «magnate» ${ }^{20}$.

Con respecto a las palabras para designar otros mandos de forma genérica, no encontramos ni una sola vez el término francés Offizier, del que Helbling ${ }^{21}$ asegura que aparece ya en 1550 bajo las grafías Officier, Offizir u Officierers; a pesar de que Schertlin sirvió durante muchos años en el ejército francés. Con este sentido sólo encontramos una voz alemana: furleut (pág. 163).

Al mando de una compañía se encontraba un hauptmann (pág. 11), cuyo plural era hauptleut (pág. 15), similar rango tenían los bevehlsleut (pág. 12) (siempre lo hemos encontrado en plural). Si se estaba al mando de una unidad de caballería se era reuter hauptmann (pág. 38) o ritterhauptman (pág. 173) y, si se estaba embarcado, hauptschiffman (pág. 159); también aparecen otras formas como ober-

17 «... Die Nachbildung General Oberst erscheint seit Fronsperger 1555 Kriegsreg. 2b, die Kürzung general seit Dilich 1608 Kriegsb, 34». Friedrich Kluge. Etymologisches Wörterbuch der deutschen Sprache. 19 Auflage bearbeitet von Walther Mitzka. Walter de Gruyter \& Co. Berlin 1963, pág. 326.

18 «titel eines höchstcommandierenden und feldherrn» Grimm op. cit. págs. 1672-1674, t. 12.

19 Paul Horn. Die deutsche Soldatensprache. Alfred Tôpelmann. Gießen 1905.

20 «Hans, ein mann der dem stande und vermögen nach etwas rechtes ist» Grimm op. cit. pág. 456, t. 10.

21 Helbling op. cit. pág. 23. 
hauptmann (pág. 87) y kriegshauptman (pág. 168). Para «lugarteniente» encontramos repetidamente la forma de origen italiano locotenent (pág. 11) o locotenet (pág. 93) ${ }^{22}$, más escasa es la denominación de origen francés leutinant (pág. 35); aunque también usa expresiones de origen alemán como: fenderich (pág. 96), y fendrich en la voz ritterfendrich (pág. 38).

$\mathrm{El}$ «jefe de la artillería» era llamado büchsenmaister (pág. 129) aunque esta voz puede significar simplemente «artillero»: etliche büchsenmaister (pág. 36).

Schertlin nos da otras denominaciones de cargos importantes en el ejército: Justitia (pág. 43), encargado de administrar justicia; musterherr (pág. 29), ocupado de la contratación de la tropa y que era ayudado por un musterschreiber (pág. 66); los consejeros de guerra o kriegsräter (pág. 35); prouosen (pág. 51) encargado del orden en el regimiento ${ }^{23}$, que tenía a su mando a un grupo de soldados llamados stecken knecht (pág. 29), encargados de castigar a la tropa con bastones (Stecken) ${ }^{24}$, y el brandschatzmaister (pág. 29) que regulaba y llevaba a cabo la Brandsatzung, práctica ejercida por los ejércitos, desde la Edad Media hasta bien entrado el siglo XVIII, consistente en exigir una cantidad de dinero en tierras enemigas bajo la amenaza de saquear y quemar sus bienes ${ }^{25}$. Encontramos igualmente la variante gráfica erprandschatzt (pág. 88). Schertlin emplea también la voz ranzion (pág. 103) con el sentido de «rescate» ${ }^{26}$.

Ya hemos visto como la palabra fendlein puede denominar a una unidad de infantería; la hallamos en expresiones como fendlin knecht (pág. 2), 4 fendlin Niederländer (pág. 22), 5 fendlein fussvolk (pág. 43), etc. Con respecto a la terminología para designar a la caballería, usa, normalmente, la expresión pferd con el valor de «soldado a caballo» en expresiones como 25 pferde (pág. 14), ringen pferde (pág. 2), gerüsteten pferden (pág. 2) y schütze zu ross (paǵ. 103). Curiosamente esta abundancia de la voz Pferde se opone a la aseveración de Helbling ${ }^{27}$ al dar 8 términos para «caballería» entre los que no aparece Pferd.

Nos encontramos con que distingue dos tipos de soldados a caballo, además de los schützen zu ross (pág. 103): los gerüsteten Pferden y los ringen Pferden; la primera expresión con formas como gerüsteten pferden (pág. 2) o 1600 gerüsten (pág. 11) indica «caballos armados de forma pesada» con armaduras y arreos medievales; los ringe pferde hace referencia a «caballería ligera» armada con corazas de menos peso y con armas de fuego. El adjetivo ringe proviene del sustan-

22 «Einzelne Schriftsteller bevorzugen die italienische Form «Locotenent, andere die Französische «Lieutenant» die noch als «Leutenant» «Lütenant» «Leutienandt» erscheint. Helbling ib. pág. 23.

23 «militärisch (früher) der mit der regimentspolizei beaufgragte» Grimm op. cit. pág. 2163 t. 13.

24 «ein Untergebener des profossen, der Zuchtigungen mit ruthen (stecken) vorzunehmen hat» Grimm ib. pág. 1350 t. 17.

25 Georg von Alten. Handbuch für Heer und Flote. Enzyklopädie der Kriegswissenschaften und verwandter Gebieter. Berlin. Deutsches Verlagshaus Bong \& Co. 1913. pág. 475 t. 2.

26 «durch lösegeld befreien, auslösen» Grimm op. cit. pág. 133 t. 14.

27 Estos términos son: «Ritter», «Ritterschaft», «die Reisigen», «Reisigen zeug», «des reising haufen», «die Hauffen zu Roß», «Reiter», «Kriegßvolk zu Pferd» Helbling op. cit. pág. 25. 
tivo femenino Die Gering (la ligereza) ${ }^{28}$. Las expresiones como kürisser (pág. 3) o cürisiern (pág. 11) hacen referencia también a un tipo de caballería armada con una coraza.

Schertlin nos da, a su vez, otros términos para designar a «la caballería», usa la forma asimilada al alemán de la voz holandesa Ruiter, que aparece como reutern (pág. 4), siempre con una t y no con dos, que es como nos la da Helbling ${ }^{29}$; nos encontramos esta voz aislada o asociada a otras voces como regementern reuter (pág. 40), geschwader reuter (pág. 55). Más alejadas de las formas actuales son denominaciones como reichs raisigen (pág. 12), 1000 raysigen pferd (pág. 12), raysigen zeug (pág. 93), etliche meiner raisigen knecht (pág. 44); el término Reisigen es definido en el Diccionario de los hermanos Grimm como «der bewaffnete vor allem der bewaffnete zu pferd ${ }^{30}$. Otras voces son $z u$ Roß en expresiones como zu ross und Fuss (pág. 3), reitschafft (pág. 94) y una sola vez la forma ritterschafft (pág. 69) que Helbling da como más común ${ }^{31}$. Tenemos también otras denominaciones que podíamos decir específicas de diferentes cuerpos militares a caballo como las denominaciones de husar (pág. 2) y en Plural husser (pág. 65).

Encontramos gran variedad de vocablos para designar al combatiente individualizado, además de los más numerosos y lógicos para la época como son knecht y landsknecht, así hallamos con frecuencia denominaciones con Personen, así 100000 personen (pág. 3), personen gemacht 8000 (pág. 22), e incluso 1200 personen landsknecht (pág. 30). También vemos con frecuencia la denominación Mann, como dreymal hundert tausend man (pág. 9), y otros. A veces Schertling denomina a los soldados por su gentilicio: Franzosen (pág. 3), Hispanier (pág. 3), samt knechten, (Teutschen), Hispaniern, und reutern, 18000 stark (pág. 4), 35000 Franzosen su ross und fuss (pág. 26), 13000 Bohämen (pág. 64), einem regiment Flaminger (pág. 95), 4000 graupunter (pág. 27), Schweizer (pág. 3), Italianer (pág. 26). Es curioso constatar como distingue entre los suizos y los de Graubunden cuando todos son suizos, quizas se deba a la forma de contratación, combate o vestimenta.

Para «infanteria» Schertlin usa fussfolck (pág. 64) y para «infante» knecht (pág. 2) y landsknecht (pág. 22); sólo a partir de la guerra de los 30 años tomará carta de naturaleza en la lengua alemana la voz española Infanterie ${ }^{32}$.

Entre las denominaciones particulares del soldado de infantería tenemos doppelsöldner (pág. 41). Se trataba de soldados que se colocaban en la primera y en la última fila de las formaciones de lansquenetes, llevaban una pesada armadura y su misión consistía en detener el primer envite de las picas de la formación contraria; de ahí que recibieran una remuneración más elevada ${ }^{33}$. Para designar a

28 Explicando además «Schriftdeutsch nur in alterer Sprache gebräuchlich doch mundartlich bewahrt». Grimm op. cit. pág. 994 t. 11.

29 Helbling op. cit. pág. 25.

30 Grimm, op. cit. pág. 745 t. 14.

31 Helbling op. cit. pág. 25.

32 Kluge op. cit. pág. 326.

33 Georg von Alten. op. cit. pág. 816, t. 5. 
un combatiente no profesional y poco especializado usa las formas paurn (pág. 22) y los cuasi sinónimos lanndvolk (pág. 9) y böfel (pág. 150).

Encontramos también la voz Gesellen formando un compuesto mitgesell (pág. 38) o asociada a adjetivos wohl geruster gesellen (pág. 10), guter gesellenn (pág. 46); su significado abarca los actuales de «compañero» y el de «soldado».

No tropezamos ni una sola vez con palabras como Kriegsman y Kriegßknecht que Helbling da como más comunes ${ }^{34}$, ni tampoco la voz Soldat.

Muy interesante son los préstamos del italiano unidos a palabras alemanas; Schertlin llama guardiknecht (pág. 7) a las tropas, - ya en aquella época suizasque custodiaban al Papa. Cuando al final de la vida de Schertlin su hijo Sebastián escriba las últimas páginas de las memorias, utilizará el vocablo guarden (pág. 174) para designar a parte de las tropas que se hallaban presentes en el entierro de su padre; se refiere con esta voz a un tipo de soldados de la ciudad de Augsburg. En este texto la voz guarden va acompañada de la de ainspenniger (pág. 174) que aparece como Einspänner en el Schwäbisvres Wörterbuch de Hermann Fischer con el significado de «Berittene Stadtwacht» ${ }^{35}$; si unos, los segundos, son «la guardia de una ciudad a caballo», los primeros serían probablemente la misma guardia de una ciudad pero gentes de a pie. Esta acepción de guarden no la da Helbling para quien significa sólo «guardia de una personalidad» o «tropas de élite» ${ }^{36}$.

Schertlin se atreve a poner algunas unidades especiales de combate con su nombre particular, sin especificar ni explicar nada, así: Janitschar (pág. 20) ${ }^{37}$. También se distingue a los trabanten (pág. 22) ${ }^{38}$ como a un cuerpo de escolta.

Para los soldados armados con armas de fuego encontramos las expresiones hackenschützen (pág. 6), y la de hackenschutzen knecht (pág. 65), que serían nuestros «arcabuceros»; da también, a veces, la denominación schützen (pág. 35), que se puede traducir por «tiradores», con lo que no queda especificado que tipo de armas disparaba, aunque dada la época en que se escribe el texto, y teniendo en cuenta el proceso de sustitución de los arcos y ballestas por armas de fuego, no pueden ser más que arcabuces.

El ejército estaba dividido en regiments (pág. 38), así nos encontramos expresiones como regiment knecht und reuter (pág. 34), regimentern zu ross und zu fuss (pág. 44), mein regement (pág. 87). Tratándose de la caballería esta podía estar dividida en geschwäder (pág. 55), geschwader reuter (pág. 55).

Acabadas las denominaciones de los mandos y tropa vamos a enumerar ahora algunas de las expresiones que usa Schertlin para indicar acciones o situaciones

34 Helbling op. cit. pág. 22.

35 Hermann Fischer. Schwäbisches Wörterbuch. Tübingen, pág. 648-649, t. 2.

36 Helbling op. cit. pág. 23.

37 Se trata de los genízaros, unidad de infanteria de élite del ejército turco cuyos combatientes eran secuestrados de niños, muchas veces en territorios cristianos, que se ocupaban de la guardia del sultán. G. R. Elton. La Europa de la Reforma. Siglo XXI de España Editores. Madrid 1984, pág. 165.

38 «im frühen 15. Jh. aufgekommen, ungeklärter Herkunft (meist zurückgeführt auf tschech. drabant 'Fußsoldat'. [...] stehenden Mitglieder des (bewaffneten) Gefolges und Gesindes im Sinne von 'Leibwächter, -diener'... Schulz op. cit. pág. 327 t. 4. 
propias de los ejércitos. Encontramos un cierto número de términos que no presentan mayor interés por ser conocidos y usados con identico sentido en el alemán actual, he preferido dejar fuera este grupo de voces para centrarme en las más novedosas y originales.

Con respecto a las expresiones que usa Schertlin para los significados de «reclutar soldados», encontramos una expresión muy interesante: knecht vergarten (pág. 35), que Hegaur ${ }^{39}$ hace venir de garten = streifen, behausen y se podría traducir por «reunir», «alistar peones». Nos da también la expresión reuter vfbringen (pág. 66) que he traducido por levar jinetes. Utiliza así mismo formas menos llamativas como knecht versameln (pág. 35), 1000 knecht in werbung (pág. 61), gemustert (pág. 22), werbung (pág. 35); los «lugares de reclutamiento» son los musterplätzen (pág. 35).

Para los gastos que ocasionaba un ejército en movimiento se necesitaba lauffgelt (pág. 87) para hacer «la marcha» o der lauff (pág. 2), en esta situación los peones están im lauff (pág. 164). Encontramos también la voz Lauf con el valor de «contratación», «alistamiento de tropas», es waren auch die leuft seltsan (pág. $33)$.

Si las tropas pagaba sus propios costes de desplazamientos se usa la expresión $v f$ jren aignen zaum gezogen (pág. 148) ${ }^{40}$. Cuando el mando recortaba el presupuesto para mantener el ejército podía ser hacer rabatti ${ }^{41}$ así en $d$ weil mir gegenn winter de konig mein regenent geschwecht, [...] rabatti gemacht, ... (pág. 101). Mientras aprovisionar al mismo era prouandiert (pág. 86). Estas dos últimas expresiones son usadas por Schertlin de forma excepcional; una sola vez en cada caso.

La palabra cassieren en nuestro contexto tiene el valor de «despedir», «licenciar a las tropas», das kriegsvolk, das unns nit dienen wöllen, hab ich cassiert. (pág. 39) ${ }^{42}$. Para hablar de las remuneraciones en metálico que recibía usa palabras como dienstgelt (pág. 33), además de otras nada novedosas. Aposentar a las tropas es quartieren ${ }^{43}$, en la expresión alle lehen vnnd dienstleute zu ross gequartiert (pág. 131).

Tenemos un grupo de palabras de menor uso como gesellen Rit (pág. 5), la cual en el Diccionario de los hermanos Grimm aparece como «acción de cabalgar en común» ${ }^{44}$. En nuestro texto puede emplearse con el valor de «hacer un servi-

39 Hegaur op. cit. pág. 281.

40 «Meisterlin chron. v. Nürnberg in chron. dtsch. städte 3,44; so denn: (zogen) auf ir selbs zawm (d. h. auf eigene kosten)». Grimm op. cit. pág. 400 t. 31.

41 La palabra Rabatt aparece a mitad del siglo XVII tomada del italiano rab(b)atto y del francés rabat. Era, al comienzo, un término específico del lenguaje de los comerciantes y tenía el mismo sentido que nuestra rebaja. Schulz op. cit., pág. 107, t. 3.

El «Dictionnaire alphabétique et analogique de la langue française» de Paul Robert no nos ofrece más información. Sólo a través de Rabatt puede tener sentido nuestra palabra aunque en el momento que Schertlin escribió sus memorias no fuera usada aún en alemán.

42 «aufheben, ungültig machen in der Kanzleisprache schon des 16. Jahrhs. aus spätlat, cassare entlehnt. Später bes, beim Militär soviel wie 'aus seine Amt entlassen, abdanken'». Schulz op. cit. pág. 338 , t. 1.

43 «Herberge nehmen, Soldaten einlegen, einquartieren» Schulz op. cit. pág. 63, t. 3.

44 «gemeinsamer ritt» Grimm op. cit. pág. 4042, t. 5. 
cio de escolta» por más que nos lo encontremos como eufemismo de «cabalgada», «algarada». Con el mismo valor tenemos reuterdienst (pág. 159). Así mismo gesellendienst (pág. 5), que en el diccionario de los hermanos Grimm aparece «como servicio corporal» ${ }^{45}$, se usa también como eufemismo de "correría», "algarada»; reuterspiel (pág. 17) tiene el sentido de «combate», «lucha a caballo».

Encontramos la palabra reuterei asociada a rauben, en rauben und reuterei (pág. 114); la única acepción que hemos encontrado para este término es la de «acción de guerra a caballo» ${ }^{46}$, acepción que no nos satisface en éste contexto; aquí reuterei sólo puede tener el mismo valor semántico que rauben. gesellenritt sería «cabalgada», «acción de despojo y guerra rápida de soldados a caballo que actúan de una forma legal o, al menos no penada por la ley», y reuterei la misma acción de despojo hecha ahora por unos delincuentes a caballo. En el primer sentido prima el de Gesellen (compañero, camarada, soldado) mientras que en el segundo el de la acción contra la ley.

Siguiendo con la pormenorización de acciones bélicas aparecen adverbios o adjetivos derivados del sustantivo Ritter usados como sinónimos de acciones relativas a la guerra, así rittermesigen sachen (pág. 16) tiene el significado de «cuestión o cosa guerrera», con la misma significación encontramos kriegssachen (pág. 70). La expresión ritterlich getroffen (pág. 17) es traducible por «nos encontramos en el campo de batalla», «peleamos», «luchamos»; lo mismo significa treffen (pág. 55) y fechten (pág. 152). Mientras tätlicher hand (pág. 120), gewaltsamlich (pág. 119), gewalttätiger Hand (pág. 119) tienen el valor de «violentamente» o «con violencia».

Handel (pág. 32) con el plural en hendel (pág. 6) que aparece en la expresión hatten von morgen biss zur mitternacht hendel mitainander (p. 6), tienen el sentido de «combate». La voz Der Schwall que en alemán actual significa «crecida», «torrente», «avenida», «diluvio» es usado por Schertlin con el mismo significado de «ataque» o «acometida» en la expresión damit ich mich des grossen schwals erwehren möcht (pág. 18). ubereylen (p. 41), fuera de su valor actual, significa en nuestro texto sorprender, denen (500 hispanisch hakenschützen) haben wir [...] ainem regement knecht und etlichen reutern [...] nachgeschickt, sie zu ubereylen (pág. 41).

Curiosa parece la expresión in harnasch und grossen krieg (pág. 167) que sólo se deja traducir por «guerra». Tenemos también el verbo achsten (pág. 36), formado sobre sustantivo die Axt y que hemos traducido por la perífrasis «dar con el hacha», acción con la que se comienza el asalto a un castillo.

La palabra Anstand, fuera del significado actual de «comportarse como corresponde a las buenas costumbres», o «del lugar donde el cazador espera a la caza», tiene, en nuestro texto, el valor de «tregua» ${ }^{47}$. Auf mitwoch und dornstag [...] machten die von Augsburg ainem anstand auf 14 tag, (pág. 14).

45 «eine frohnleistung» Grimm ib. pág. 4044, t. 5.

46 «in älterer sprache ein reiterisches unternehmen, besonders kleinerer fehdezug...» Grimm ib. pág. 782 , t. 14 .

47 «cessatio, mora, induciae im $16.17 \mathrm{jh}$. vorherschend waffenstillstand, austehen des krieges...» Grimm ib. pág. 473 t. 1. 
Schertlin usa la expresión sind mit weissen staben abgezogen (pág. 92) que no puede significar más que «se retiraron con bandera blanca».

Merecen especial atención las expresiones sinónimas one schwertschlag (pág. 14) o one alle schwertstraich (pág. 60) que tienen el significado de «sin violencia», «sin lucha».

Otro de los grupos de palabras militares que hemos hecho hace referencia a los lugares de combate y defensa. La voz Blockhaus se puede traducir por el germanismo admitido de «blocao» que Schertlin usa como plochhaus (pág. 48) con él sentido de «construcción de madera» y hoy tiene el de pequeña construcción hecha de cualquier modo ${ }^{48}$; encontramos también el plural de esta voz plochheusern (pág. 150).

La palabra Berg en la expresión besetzt die berg vnd werin (pág. 56) tiene el sentido de "pequeñas elevaciones de terreno» ${ }^{49}$, en otros párrafos aparece esta voz con identico significado; como otras fortificaciones que merezca la pena destacar tenemos castell (pág. 153), palabra de claro origen italiano.

Usa la forma undergraben (pág. 103) como un sustantivo en plural hoy inexistente y con el significado de «zanja», «excavación»; hace también derivar el sustantivo plural sprengen (pág. 103) del verbo sprengen con el sentido de «minas».

Merece la pena destacar dos cultismos latinos: nauen (pág. 159) y Victoria (pág. 163) que usa una sola vez. Encontramos varias denominaciones para «mensajeros»: trometer (pág. 29) y trommeter (pág. 147), que no es sólo «el encargado de hacer sonar la trompeta para que la tropa obedeciera las órdenes de sus mandos», sino también es usado como «mensajero» ${ }^{50}$, ...hab mein trometer hinein geschickt, mit ynen sprach zu halten beghrt (pág. 41). El mismo valor por tanto que las voces herolt (pág. 35), y edlen knabe (p. 42) que tienen un valor semántico ennoblecido con respecto a la anterior; pues se trata en ambos casos de enviados del emperador. nachrichter (pág. 29) y postboten (pág. 36) parece corresponder a nuestro correo, su misión sería la de hacer de enlace.

El significado que nos da el Diccionario de los hermanos Grimm ${ }^{51}$ para verreisen, de donde proviene verrissen (pág. 69), «caer al suelo», «caer desde arriba», no encaja perfectamente en nuestro texto, donde sólo puede tener el sentido de «derribar», ...cassel Giessen und Risslishaim verrissen, ... (pág. 69).

Ha sido difícil de descifrar el sentido de gewarsam, en la frase vnd mit meinen reutern bis an ir gewarsam gepracht (pág. 27), hoy tiene el sentido de «custodia», «prevención», «arresto», aunque teniendo en cuenta nuestro contexto únicamente se puede traducir por «sus líneas», «su campo» o, quizás, «su seguridad».

Por último nos queda la voz halt, que encontramos en la expresión druch derfeind halt hindurch vber die bruckenn gezogenn (pág. 63). Halt sería un sus-

María Moliner. Diccionario de uso del español. Editorial Gredos. Madrid 1983, págs. 385-386, t. 1 .

49 «auch andere erhöhungen und anhäufungen nennt man berge» Grimm op. cit. pág. 1504, t. 1.

50 «in besonderer verwendung als bote, befehlsübermittler,...» Grimm op. cit. pág. 845, t. 22.

51 Grimm op. cit. pág. 1003, t. 25. 
tantivo del verbo halten y no se puede traducir más que como «parada» con la acepción de «pequeño campamento» ${ }^{52}$.

A modo de conclusión podemos decir que el lenguaje de Schertlin es, en líneas generales, poco innovador, en cuanto al uso de vocablos extranjeros. Aunque a veces nos sorprenda introduciendo palabras como General o Armada que no se habían generalizado aún en la lengua alemana. Tenemos que pensar que esta tendencia es en él deliberada, pues vivió y luchó junto con españoles, italianos y franceses en Flandes, Austria, Italia y Francia. Tampoco encontramos muchos cultismos entre las voces militares a pesar de su probado conocimiento del latín - estudió durante varios años en la Universidad de Tübingen-. No usa, felizmente, excesivos dialectismos que resultan muy difíciles de desentañar. Tenemos, por tanto, una lengua muy interesante, que requiere un constante esfuerzo de matización con respecto al vocabulario actual y con un nivel de estandarización que nos permite acercarnos, con garantías, al léxico típico del Frühneuhochdeutsch.

52 «halt geht daher auch auf den ort, wo halten gemacht wird und man sich lagert odert brigt und ist namentlich der technischen sprache einer streitbaren truppe eigen». Grimm op. cit. pág 271, t. 10. 
GLOSARIO

achsten

admiral

ainspennigen

Alewaschant

anstand

12 apostel

armada

arme

Bartanwascha

Bassa

Behämen

berg und werin

bevelhsleuten

böfel

brandschatzmaister

büchsenmaisternn

etlichen büchsenmeistern

bulfer, kugeln, ...vnd munition

bürschbüchsen

cassieren

castell

conestable

Cuarthonen

curisierern

degen

dienstgeldt

dolch

doppelhaken

doppelsöldner

edlen knabe

erprandschatzt

falconet

faustbuchsen

fausthamer

fechten

feldgeschützt

feld marschalck fenderich / fendrich

fendlein / fendlen

fendlin Niederländer

fendlin Knecht

fendlein fussvolk

feuerbüchsen

Flaminger

Franzosen

Franzosen zu ross und fuss

furleut

fuss

zu ross und fuss

fussgeendem volk

fussvolck

gemustert

general

general capitain

general obrister feldhauptman

gequartiert

gerüsten

gerüsten pferden

geschütz

gross und klein geschützt

schwere geschutz

geschwader

geschwader reuter

gesellen

guter gesellen

geruster gesellen

mitgesell

gesellendienst

gesellen Ritt

gesind

hofgesind

gewarsam

gewaltsamlich

gwalttätiger hand

graupunter

grob geschütz

grossmarschalk

guarden 
guardiknechten

hackenschützen

hackenschutzen knecht

halt

handel

handtgeschütz

handschuh

hantror

hansen

gross und cleine hansen

harnasch

jos barnasch vnd grossen Krieg hauf

halb hauf

haufen

heufen zu ross und zu fuss

gaistlichen hauffen

hallen hauffen

Kay. may. hauffen

Konigs haufen

schwabischen pundts hauffen

hauptfane

hauptleut

hauptmann

hauptpanier

hauptschiffman

heer

ein aigen her

höres kraft

heresmacht

herszug

helleparten

helmlin

hendel

hendtschuh

herolt

Hispanier

husar

husser

Italianer

Janitscharen

justicia knecht

etliche meiner reisigen knecht

knecht vergarten

knecht versameln

knecht in werbung

knechten

kriegshauptman

kriegsleuten

kriegsräten

kriegssachen

kriegsvolk

kugel

kürisser

landsknecht

landvolk

lauffgeld

lauf

jm lauff

leutinant

locotenent / locotenet

lot

dreymal hundert tausent man

marschalck

munition

musterher

musterplätzen

musterschreiber

nachrichter

nauen

oberhaupiman

oberst

obrist / obrister

obristfeldmarchalckamt

obristen locotenent

obrister

kraiss obrister

obrister feldhaupman

obrister feldher

obrister leutenant

ochiali 
paurn

personen

personen gemacht

personen landsknecht

pferde

platten

plei

plochhaus

plochheusern

postbotten

prouandiert

prouosenn

Quartonen

rabatti

raisigen

reichs raisigen

raisigen knecht

etlichen meinem raisigen knechten

raysigen pferd

raysigen zeug

raitschafft

ranzion

raubens und reuterei

regement

regement knecht und reuter

regementern reutern

regementern zu ross und zu fuss

regements

rennfane

reutern

reuterdienst

reuter hauptmann

reuterspiel

reuter vfbringen

ringehpferde

ritter fendrich

ritterhauptman

ritterlich troffen

rittermesigen sachen

ritterschafft

rittersporen

ross

zu ross und fuss säbel

schäfflin

schuch

schutze

schützen zu ross

schwals

schweitzer

schwert

schwertschlag

schwertstraich

seiten weren

singerin

spiss / spiess

sporen

sprengen

staben

mit weissen staben

stark

über 12.000 starck

stecken knecht

stuck reder

stuckbüchsen

stücklin büchsen

stücklin büchsen auf rädern

sturmhut

tätlicher hannd

thuch

trabanten

treffen

trometer

trommeter

ubereilen

vfbringen

undergraben

vergarten

verrissen

versameln

verldhern

Victoria

volk

bapsts volk

fussgeheendem volk 
übelgezogens verzagts volck werbung

\section{zaum}

$v f$ jrem aigenen zaum gezogem zeugmaister 